University of Nebraska - Lincoln

DigitalCommons@University of Nebraska - Lincoln

Community and Regional Planning Program:

Faculty Scholarly and Creative Activity

Community and Regional Planning Program

$1-2010$

\title{
Moving from agenda to action: Evaluating local climate change action plans
}

\author{
Zhenghong Tang \\ University of Nebraska - Lincoln, ztang2@unl.edu \\ Samuel D. Brody \\ Texas A\&M University \\ Courtney E. Quinn \\ University of Nebraska-Lincoln,, cquinn@unl.edu \\ Liang Chang \\ University of Illinois at Urbana-Champaign, \\ Ting Wei \\ University of Nebraska-Lincoln,
}

Follow this and additional works at: https://digitalcommons.unl.edu/arch_crp_facultyschol

Part of the Urban, Community and Regional Planning Commons

Tang, Zhenghong; Brody, Samuel D.; Quinn, Courtney E.; Chang, Liang; and Wei, Ting, "Moving from agenda to action: Evaluating local climate change action plans" (2010). Community and Regional Planning Program: Faculty Scholarly and Creative Activity. 6.

https://digitalcommons.unl.edu/arch_crp_facultyschol/6

This Article is brought to you for free and open access by the Community and Regional Planning Program at DigitalCommons@University of Nebraska - Lincoln. It has been accepted for inclusion in Community and Regional Planning Program: Faculty Scholarly and Creative Activity by an authorized administrator of DigitalCommons@University of Nebraska - Lincoln. 
Published in Journal of Environmental Planning and Management 53:1 (January 2010), pp. 41-62;

doi: 10.1080/09640560903399772 Copyright (C) 2010 University of Newcastle upon Tyne; published by Routledge/Taylor \& Francis. Used by permission. http://www.informaworld.com

Submitted January 19, 2009; final version submitted April 26, 2009.

\title{
Moving from agenda to action: Evaluating local climate change action plans
}

\author{
Zhenghong Tang \\ Community and Regional Planning Program, 302 Architecture Hall, College of Architecture, \\ University of Nebraska-Lincoln, Lincoln, NE 68588-0105
}

\section{Samuel D. Brody}

Environmental Planning \& Sustainability Research Unit, Hazard Reduction \& Recovery Center, Department of Landscape Architecture \& Urban Planning, Texas A\&M University, College Station, TX 77843-3137

\section{Courtney Quinn}

School of Natural Resources, University of Nebraska-Lincoln, 3310 Holdrege St, Lincoln, NE 68583-0961

\section{Liang Chang}

Department of Civil Engineering, University of Illinois at Urbana-Champaign, Urbana, IL 61801

\section{Ting Wei}

Community and Regional Planning Program, 302 Architecture Hall, College of Architecture, University of Nebraska-Lincoln, Lincoln, NE 68588-0105

Corresponding author - Z. Tang, email ztang2@unl.edu

\begin{abstract}
Climate change is conventionally recognized as a large-scale issue resolved through regional or national policy initiatives. However, little research has been done to directly evaluate local climate change action plans. This study examines 40 recently adopted local climate change action plans in the US and analyzes how well they recognize the concepts of climate change and prepare for climate change mitigation and adaptation. The results indicate that local climate change action plans have a high level of "awareness", moderate "analysis capabilities" for climate change, and relatively limited "action approaches" for climate change mitigation. The study also identifies specific factors influencing the quality of these local jurisdictional plans. Finally, it provides policy recommendations to improve planning for climate change at the local level.
\end{abstract}

Keywords: climate change, local jurisdiction, action plan, quality

\section{Introduction}

Climate change is now widely recognized as an important global problem expected to have adverse impacts on both the natural and human environment (IPCC 2007). Local efforts have profound implications for climate change and can contribute significantly to global efforts to reduce greenhouse gas (GHG) emissions (APA 2008). Local jurisdictions have the ability to influence development activities and have direct control over emissions resulting from municipal operations. In fact, many localities in the US are already taking action to reduce greenhouse gas emissions. Some recent studies have advanced our understanding of how communities can most effectively address the issue of climate change (Lindley et al. 2006, Moser and Tribbia 2006, Moser and Luers 2008, Travis 2008). For ex- 
ample, local climate change action plans are critical for providing a fundamental inventory for GHG emissions, setting a long-term emission reduction target, making appropriate action policies, coordinating cross-boundary issues and implementing decisions. The most recent research highlights the criticality of making adaptations in the next several decades before mitigation measures can have an effect (Stern 2007); however, research on local actions is lagging behind climate impact assessment.

In 1992, more than 178 governments at the United Nations Conference on Environment and Development (UNCED) signed Agenda 21, a milestone plan of action to be taken globally, nationally and locally in every area in which humans impact the environment. The Local Agenda 21 (LA21) is a part of the global Agenda 21. A LA21 plan is a strategic comprehensive plan of action established by a local government through participatory measures to ensure environmental protection, economic prosperity, and social equity. In 2002, Local Agenda (LA21) advanced to the next phase-Local Action 21. Local Action 21 emphasizes an accelerated implementation of sustainable development. These actions include: (1) identifying and removing barriers (e.g. poverty, injustice, conflicts and an unhealthy environment) to sustainable development; (2) reducing depletion of resources and environmental degradation; and (3) ensuring effective implementation, monitoring and continual improvement. Climate change mitigation and adaptations are the critical part of the Local Action 21. An increasing number of local jurisdictions have recognized that global climate change has a critical local dimension. By August 2008, there were 850 mayors from 50 states, the District of Columbia and Puerto Rico, representing a total population of almost 80 million citizens, who have signed the US Conference of Mayors Climate Protection Agreement ( http://www.usmayors.org/ climateprotection ). Furthermore, 157 local jurisdictions in the US have joined the Cities for Climate Protection тм (CCP) Campaign, which is an important part of Local Action 21 ( http://www.iclei.org/index.php?id=800 ). The CCP Campaign helps local jurisdictions to reduce GHG emissions and integrate climate change mitigation into their decision-making processes. The CCP Campaign provides an innovative performance framework for local governments to reduce greenhouse gas emissions throughout their jurisdictions. Most importantly, at least 40 of these local jurisdictions have developed local climate change actions plans (Figure 1).

The jurisdictions with local climate change action plans indicate a serious consideration and commitment for climate change mitigation. A local climate change action plan will provide a feasible, bottom-up means to establish strategic goals to lower emissions, identify emission sources and amounts, make appropriate policies and establish mechanisms for co-ordination, monitoring, measuring and reporting performance. Although many previous studies have focused on evaluating plan quality for natural hazards (Burby et al. 2000, Olshansky 2001, Nelson and French 2002, Burby 2005, Tang et al. 2008), ecosystem management (Brody et al. 2004), coastal planning (Tang 2008); sustainability (Berke and Conroy, 2000, Berke 2002, Conroy and Berke 2004), and smart growth (Edwards and Haines 2007), no research to date has empirically linked local plan quality to climate change. Furthermore, although some studies have begun to discuss the role of local policy in climate change (Bizikova et al. 2007, Burton et al. 2007, Swart and Raes 2007, Brody et al. 2008a, 2008b, Zahran et al. 2008a, 2008b), little research has directly analyzed local climate change action plans (Wheeler 2008). To date, no empirical model has measured local climate change action plan quality. In recognition of this gap in the current research, this study proposes a proactive model to empirically examine local climate change action plan quality. 


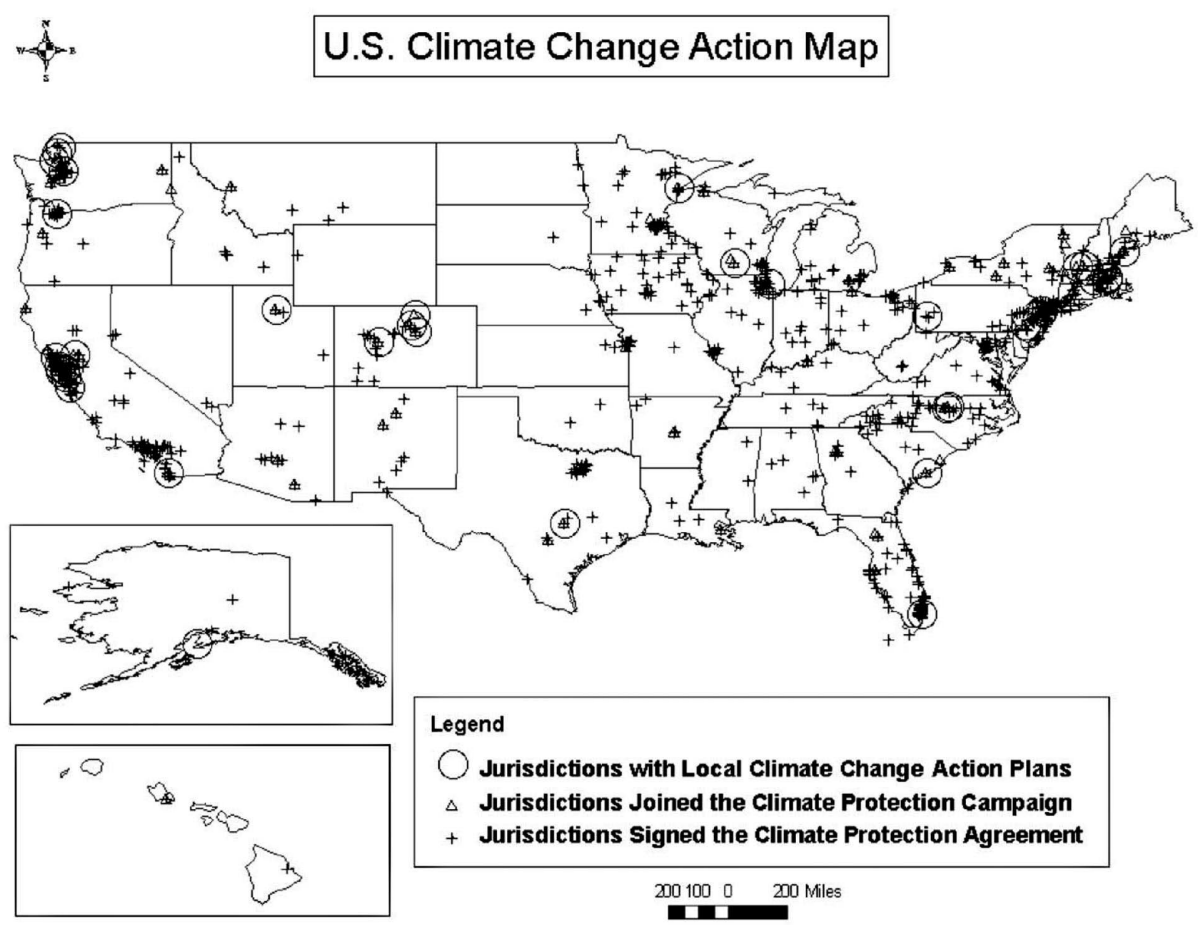

Figure 1. Status of US state and local climate change action plans (dated October 10, 2008). Notes: For a list of jurisdictions or updating information see: Jurisdictions joined the Cities for Climate Protection (CCP) Campaign: http://www.iclei.org/index.php?id=1484\&region=NA . Jurisdictions signed U.S. Conference of Mayors Climate Protection Agreement: http://www.usmayors.org/climateprotection/list.asp

Specifically, the study addresses a number of questions related to local jurisdictional efforts to mitigate climate change:

(1) To what extent do local jurisdictions indicate awareness of climate change in their local climate change action plans?

(2) How well do local jurisdictions analyze the impacts of climate change in local climate change action plans?

(3) What actions have local jurisdictions taken to mitigate and adapt to climate change, and which strategies received the greatest and least attention?

(4) Do the traditional contextual variables affect local climate change action plan quality?

(5) How can local climate change action plans be improved to address climate change mitigation and adaptations?

This study will provide important information for decision makers interested in mitigating the adverse impacts of global climate change on local communities.

\section{Conceptualizing local planning capacity for climate change}

To enhance society's preparedness for the possible adverse impacts of climate change, decision makers should recognize three critical components termed "AAA": (1) Aware- 
ness; (2) Analysis; and (3) Action (UKCIP 2003, California Climate Change Center 2006). Local climate change action plans should indicate a comprehensive awareness of climate change, make a thorough analysis of these impacts, and translate awareness and concerns into concrete action policies. These three critical components are vital for incorporating climate change mitigation and adaptation into local action plans. This study develops a conceptual framework using these three components to guide local planning capacities in addressing climate change mitigation and adaptation. The components are illustrated in Figure 2.

Awareness measures the degree to which local jurisdictions understand the concepts of climate change. Local jurisdictions need to be aware of the scientific underpinning of climate change, climate variability and global warming (Lindseth 2004). Moreover, the effects and impacts of climate change on local jurisdictions should be addressed in local climate change action plans. Finally, the long-term goals and detailed targets for GHG emissions should be included in local climate change action plans.

Analysis components should provide an emission inventory and cover the major drivers, sources or contributors to climate change (Angel et al. 1998). The analysis also should identify the base year of emissions and predict future emission trends. A vulnerability assessment should be conducted to identify the most vulnerable places and most vulnerable populations (Center for Science in the Earth System et al. 2007). The cost estimates for GHG emission reduction should also be a part of the analysis. Finally, analysis tools and software should be identified in the plans (ICLEI 2008).

The actions component of a plan should demonstrate how a local jurisdiction will reduce GHG emissions. The action strategy should identify and quantify appropriate measures to achieving a reduction in emissions. Actions should involve policies, tools and strategies to address climate change mitigation and adaptations in the natural environment, built environment and human health. These actions should include: (1) Communication and collaboration policies (Lindseth 2004); (2) Financial tools (Yarnal et al. 2003); (3) Land use policies (Betsill 2001); (4) Transportation policies (Andrews 2008); (5) Energy strategies (Andrews 2008, Nelson 2008); (6) Waste strategies (California Air Resources Board et al. 2008); (7) Resources management strategies (Mayors Climate Protection Center 2007); and (8) Implementation and monitoring strategies (California Air Resources Board et al. 2008).

These three core plan components provide a framework to guide local climate change action planning. Using this framework, a plan quality evaluation coding protocol was developed with detailed indicators within each component to explain the key points that incorporate climate change concepts was developed. When aggregated, these indicators can be statistically measured to compare the plans across multiple jurisdictions.

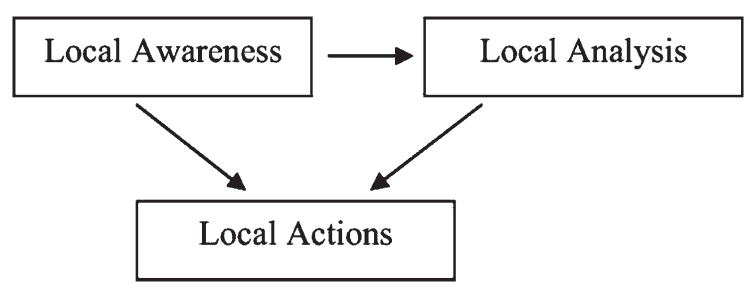

Figure 2. Conceptualizing local climate change action plan quality. 


\subsection{Explaining variation in climate change plan quality}

In addition to measuring the ability of local jurisdictions to address and plan for climate change, an explanatory model is also tested to identify the factors influencing variation in plan quality across the US (see Figure 3). The dependent variable in the study is local climate change action plan quality. It can be measured by the three plan components stated above.

Based on past research on plan quality and local climate change mitigation, multiple independent variables affecting the plan quality measure are identified. Local climate change action planning is a complex process incorporating geographic, political, social and economic settings and is usually affected by many factors including jurisdiction framework, decision-makers' values and experiences, information resources and awareness of alternatives. Although many studies have discussed the factors influencing local planning (Forester 1984, Brody 2003, Norton 2005), little research has quantitatively measured the factors influencing local climate change action plan quality. Independent variables cover three sets of traditional contextual variables to evaluate local climate change action plan quality. These independent variables - capacity variables, climate risk variables and emission stress variables - can be used to explain local climate change action plan quality.

Capacity variables include political will (Bestill 2001), state mandates (Berke et al. 1996), and community wealth (Van Liere and Dunlap 1981, Scott and Willits 1994, Brody et al. 2003, Tang and Brody 2009, Tang et al. 2009).

The first hypothesis here is that the jurisdictions with stronger political will in multiple climate change programs may have higher plan quality than others. Jurisdictions with strong political will should improve local capabilities for information access, technical support and inter-organizational co-ordination.

The second hypothesis is that a jurisdiction within a state with mandates in climate change may have higher plan quality. Planning mandates have been shown to enhance local plan quality in several previous studies (Berke and French 1994, Burby and Dalton 1994, Dalton and Burby 1994, Berke et al. 1997, Brody et al. 2003). In many instances, a topdown regulatory approach can motivate local jurisdictions to address what they may consider regional problems.

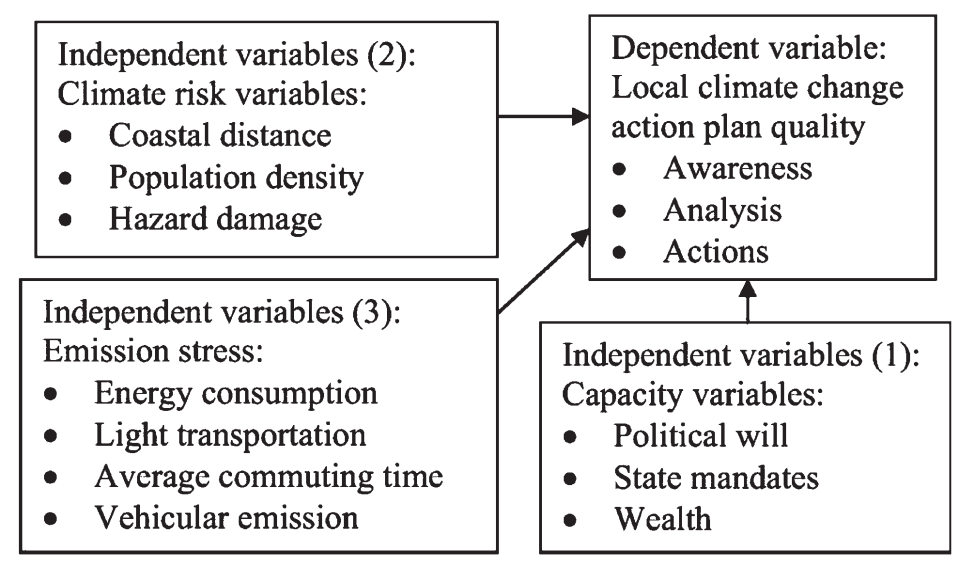

Figure 3. Conceptual model of dependent and independent variables. 
The third hypothesis is that a wealthier jurisdiction may develop a higher quality climate action plan. Wealthier jurisdictions should have more financial, human and technical resources with which to develop a high quality plan.

Climate risk variables include coastal distance (Brody et al. 2008a, Zahran et al. 2008a), population density, and hazard damage (Brody et al. 2008b, Zahran et al. 2008b).

The fourth hypothesis is that the jurisdictions located in coastal areas may have higher climate risk, leading to a higher plan quality. When a jurisdiction locates in coastal areas, it may have more coastal-related risks (e.g. hurricane and flooding).

The fifth hypothesis is that the jurisdictions with higher population density may have higher plan quality. When more people are at risk from the effects of climate change such as sea level rise or increased severe storms, it is expected that local governments will respond by protecting the public welfare with stronger climate change plans.

The sixth hypothesis is that the jurisdictions with more historical hazard damages may have higher plan quality. When a jurisdiction has experienced historical hazard damages, we expect local governments to be better prepared to deal with risks associated with climate change.

Emission stress variables include energy consumption (Brody et al. 2008a), light transportation (Brody et al. 2008a), average commuting time and vehicular emission.

The seventh hypothesis is that the jurisdictions with higher energy consumption will adopt lower quality climate change plans. Communities that rely economically on energy industries would be less concerned with mitigating the adverse effects of climate change.

The eighth hypothesis is that the jurisdictions with a higher percentage of people using light transportation will adopt higher quality climate change action plans. Localities committed to alternative forms of transportation will be more likely to be concerned over the climate change problem and adopt policies that reduce GHG emissions.

The ninth hypothesis is that the jurisdictions with higher vehicle emissions may feel pressure to develop higher quality climate change action plans. While planners may not be able to control the number of vehicles on the road, they can respond with appropriate strategies to reduce their impact on the climate change problem.

The tenth hypothesis is that the jurisdictions with higher average commuting time adopt lower quality climate change action plans. Communities with a history of sprawling development patterns and high land consumption rates may not be interested in mitigating the impacts of climate change.

\section{Research methods}

\subsection{Sample selection}

The population for this study is all of the jurisdictions in the US that have adopted a local climate change action plan. First, there was a search of websites of the jurisdictions that have joined the US Conference of Mayors Climate Protection Agreement and the CCP Campaign. Next, the information provided by the Pew Center on Global Climate Change and National Association of Counties was double-checked to find possible local climate change action plans. After systematic searching, 40 local climate change action plans were collected which were available by September 1, 2008. 


\subsection{Concept measurement}

\subsubsection{Dependent variable}

The preceding conceptualization of plan quality leads to the local evaluation coding protocol. Each component was evaluated by examining all elements of a plan to assess whether it addressed the 36 indicators categorized into the three plan components: (1) awareness; (2) analysis; and (3) action. Following the analytical approach of previous studies on plan quality, each indicator was scored on a 0-2 scale. A score of " 0 " means the indicator is not mentioned in the plan, a score of " 1 " means that an indicator is considered but not thoroughly, and a score of " 2 " means the indicator is fully considered. The equations are used to calculate plan component quality and total plan quality. ${ }^{1}$ First, the total of all indicator scores within each plan component are summed. Second, each plan component quality is standardized by dividing the total possible score in each plan component and multiplying by 10 . Third, the five plan components score is summed together to get the total plan quality.

To maintain reliability, the plan indicators were pre-tested and multiple-tested against the plan coding to reduce personal bias in measurement and judgment. Each plan was evaluated three times; the final evaluated score was adopted for each indicator. This study uses the equal weighting approach for all of the indicators.

This study also introduces indicator performance to measure each indicator's quality. Indicator performance includes two sub-items: ${ }^{2}$ an indicator breadth score and depth score. Indicator breadth measures the extent to which each of the indicators was addressed across all plans. Indicator breadth means the proportion of plans that addressed the indicator. Indicator depth measures the level of importance and analyses how much importance is stated for each indicator in a plan. Indicator depth means how fully an indicator was addressed by the plans. If none of the plans address an indicator, the indicator depth score is 0 . If at least one plan addresses an indicator, the indicator depth score is within $50-100 \%$. It indicates relatively high quality analysis for those jurisdictions who conducted the analysis.

Cronbach's Alpha was used to test inter-item scale reliability. The scale reliability can measure the correlations between the individual items that construct the scale, relative to the variances of the items. The Cronbach's Alpha for three plan components and total plan quality is listed in Table 1. Based on previous research (Nunnally 1978), this study's inter-item scale reliability reaches the acceptable level.

\subsubsection{Independent variables}

Nine independent variables are measured and analyzed to explain the variation in the climate change plan quality scores. These measurements and resources are listed in Table 2 .

Table 1. Inter-item scale reliability.

\begin{tabular}{lcc}
\hline Plan component and total plan quality & Number of indicators & Cronbach's Alpha \\
\hline Awareness & 4 & 0.754 \\
Analysis & 6 & 0.872 \\
Action & 26 & 0.947 \\
Total plan quality & 36 & 0.954 \\
\hline
\end{tabular}




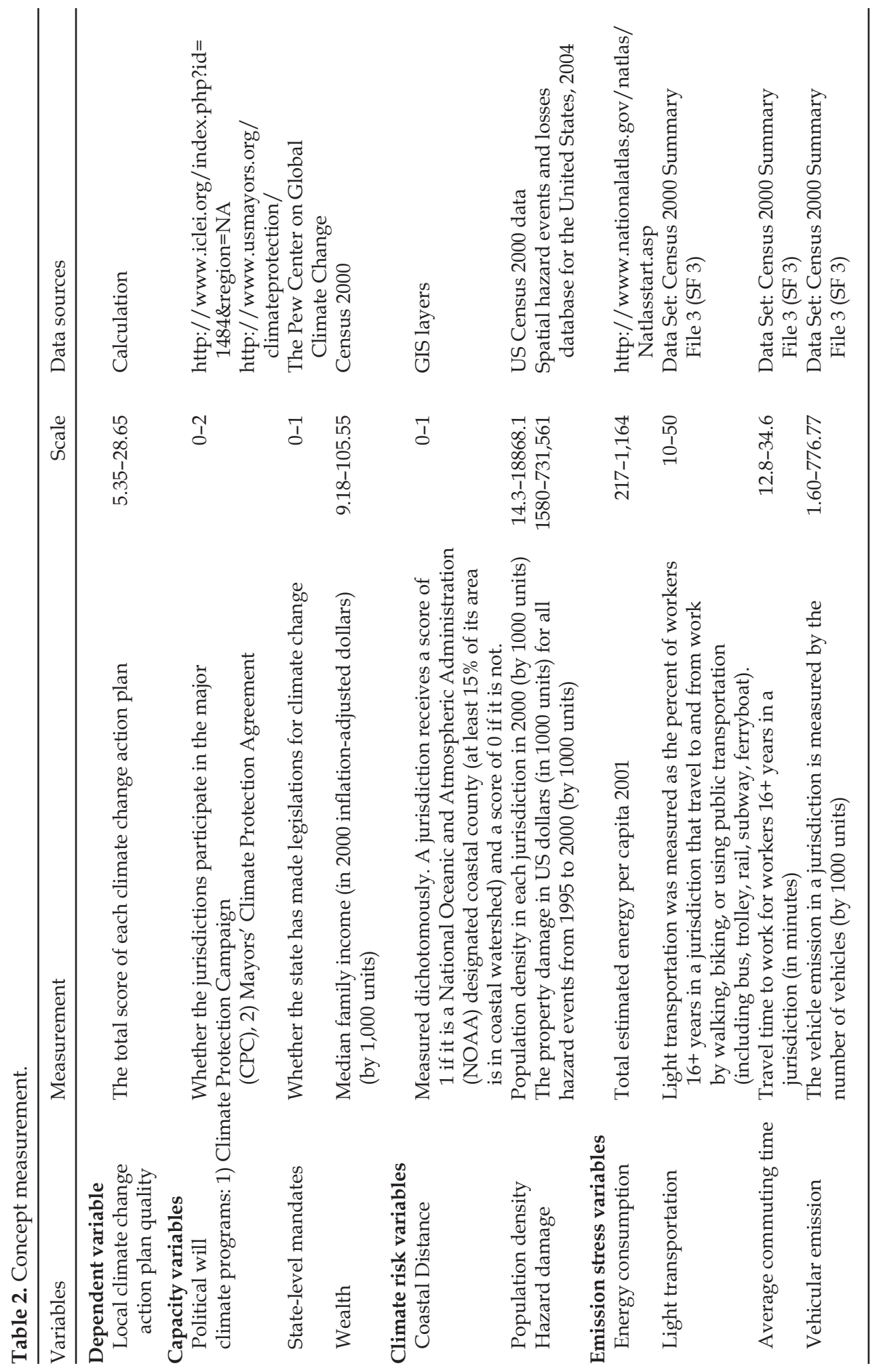


The political will variable measures whether the jurisdictions are participating in the following major climate change programs: (1) Climate Protection Campaign (CPC); (2) Mayors Climate Protection Agreement. The state-level mandate variable was dichotomously measured by whether the state has passed legislation for climate change in which a jurisdiction participates. Wealth is measured by the median family income for each jurisdiction based on the 2000 US Census.

The coastal distance variable was dichotomously measured by whether a jurisdiction is located in a coastal watershed defined by the National Oceanic and Atmospheric Administration (NOAA). Population density was measured by the number of people per square mile in a jurisdiction in 2000 as reported by the last US Census. The hazard damage was measured by the property damage in US dollars (in 1000 units) for all hazard events from 1995 to 2000 as reported by the spatial hazard events and losses database for the United States, 2004.

Energy consumption was measured by the total estimated energy use per capita in 2001 from by the National Atlas of the United States from information provided by the Energy Information Administration. Light transportation was measured as the percentage of workers aged 16 years or older in a jurisdiction that travel to and from work by walking, biking or using public transportation (which includes bus, trolley, rail, subway, ferryboat) as reported in the 2000 US Census. The vehicle emissions variable was measured by the number of vehicles in a jurisdiction, as reported in the 2000 US Census. Finally, the average commuting time was measured by the travel time to work for workers aged 16 years or older in a jurisdiction based on estimates from the year 2000 US Census.

\subsection{Data analysis}

Data were analyzed in two stages. First, descriptive statistics were used to assess the quality of the 40 local climate change action plans in the sample. Second, ordinary least squares multiple regression analysis was employed to identify which factors significantly influence local climate change plan quality. Diagnostic procedures found no violations of regression assumptions and that the ordinary least squares would yield best, linear and unbiased parameter estimates. Scatter plots and residual plots were also drawn of dependent variables versus each of the independent variables and no significant influential data points or outliers were found.

\section{Results}

\subsection{Descriptive statistics for plan quality}

As shown in Table 3, the mean total score for climate change action plan quality is 17.25, which is $57.5 \%$ of the total possible score on a scale of $0-30$. Of the three plan components,

Table 3. Descriptive statistics for total quality and components performance.

\begin{tabular}{lccrrrr}
\hline Components & $\begin{array}{c}\text { Number of } \\
\text { jurisdictions }\end{array}$ & $\begin{array}{c}\text { Number of } \\
\text { variables }\end{array}$ & Min. & \multicolumn{1}{c}{ Max. } & \multicolumn{1}{c}{$\begin{array}{c}\text { Mean } \\
(\% \text { of total })\end{array}$} & Std. Dev. \\
\hline Awareness $^{*}$ & 40 & 4 & 2.50 & 10.00 & $7.68(76.8 \%)$ & 2.10 \\
Analysis* $^{*}$ & 40 & 6 & 0.00 & 10.00 & $5.56(55.6 \%)$ & 3.09 \\
Actions* $^{*}$ & 40 & 26 & 0.00 & 8.65 & $4.01(40.1 \%)$ & 2.41 \\
\hline
\end{tabular}

* Each component possible maximal score is 10.00

** Each plan's total possible maximal score is 30 . 
awareness received the highest score $(M=7.68,76.8 \%$ of the total possible score in this component), suggesting that jurisdictions undertaking planning initiatives have strong awareness for climate change impacts and local responsibilities. The analysis component received a moderate score $(M=5.56,55.6 \%$ of the total possible score in this component), indicating local jurisdictions have undertaken some level of research analysis for climate change issues. Finally, the action plan component the lowest score $(M=4.01,40.1 \%$ of the total possible score in this component), indicating that there is still much room to improve local action policies, tools, and strategies in climate change mitigation and adaptation. In Table 4, the correlation matrix indicates that these three plan components are significantly $(p<0.01)$ correlated.

In addition, there are large variations in quality across local jurisdictions' climate action plan quality regarding climate change awareness, analysis and action. As shown in Appendix 1, the lowest three plan scores are 5.35 (Austin, TX), 6.45 (Santa Cruz, CA), and 6.83 (Evanston, IL). Most of the jurisdictions with lower scores only have abstract plans rather than full plans. In contrast, the three highest scoring jurisdictions are 25.9 (Berkeley, CA), 26.54 (Bellingham, WA), and 28.65 (King County, WA). Twenty-seven (67.5\% of 40 jurisdictions) plans in the sample scored below the 50 th percentile for total plan quality.

\subsection{Indicator performance}

\subsubsection{Indicator performance for awareness plan component}

All of the 40 local climate change action plans have identified the important concepts of climate change or global warming and GHG emissions (Table 5). An awareness and understanding of climate change issues is an important foundation for adopting specific actions to address the problem. In Table 5, most (95.0\% breadth) jurisdictions have set long-term goals and detailed targets for GHG emission reduction. In addition, the effects and impacts of climate change were addressed by a majority $(72.5 \%$ breadth) of

Table 4. Correlation matrix for three plan components.

\begin{tabular}{lccc}
\hline Components & Awareness* & Analysis* & Actions* \\
\hline Awareness & 1 & & \\
Analysis & $0.848^{* *}$ & 1 & \\
Actions & $0.840^{* *}$ & $0.512^{* *}$ & 1 \\
\hline
\end{tabular}

* Each component possible maximal score is 10.00

** indicates significance at 0.01 level.

Table 5. Awareness plan component indicator performance.

\begin{tabular}{lcc}
\hline Indicators & Breadth (\%) & Depth (\%) \\
\hline Concept of climate change or global warming & $100.0 \%$ & $88.8 \%$ \\
Concept of Greenhouse gas $\left(\mathrm{CO}_{2}\right)$ emission & $100.0 \%$ & $88.8 \%$ \\
Effects \& impacts of climate change & $72.5 \%$ & $67.2 \%$ \\
Long-term goals and detailed targets for GHG emissions & $95.0 \%$ & $85.5 \%$ \\
\hline
\end{tabular}


plans. However, a comparatively lower depth score $(67.2 \%$ depth) indicates that these plans had limited details when it comes to an awareness of potential climate change impacts.

\subsubsection{Indicator performance for analysis plan component}

A majority of plans conducted a detailed climate change analysis (Table 6). For example, $87.5 \%$ of the sample conducted a thorough emission inventory and $82.5 \%$ calculated the base-year emission and forecast future emission trends. Approximately twothirds of the plans conducted cost estimates for GHG emission reduction based on their target goals. Slightly more than half of the plans identified necessary software for emission forecasting, decision making or carbon footprint calculation. However, only $15.0 \%$ of plans conducted vulnerability assessments to geographically identify the population most susceptible to the adverse impact of climate change. The depth score for all six indicators in the analysis plan component was over $80 \%$, indicating relatively high quality analysis.

\subsubsection{Indicator performance for action plan component}

In the action component, there are large variations among policies, tools, and strategies listed by individual plans; some are well covered in current climate change action plans. However, some strategies receive little attention. Details are listed in Table 7.

4.2.3.1. Communication and collaboration policies. A majority (85.0\%) of plans identifies policies for public awareness, education and participation, but the $75.0 \%$ quality score suggests there is still room to improve this policy. The same pattern applies to identifying appropriate procedures to co-ordinate with multiple agencies (e.g. business, government, Intergovernmental Panel on Climate Change (IPCC), CCP, etc).

4.2.3.2. Financial tools. Several jurisdictions have adopted GHG reduction fees (47.5\% breadth, $68.4 \%$ depth), or establish carbon taxes (37.5\% breadth, 76.7\% depth).

4.2.3.3. Land use policies. Jurisdictions also vary in adoption of land use policies to address climate change. For example, approximately two-thirds of the sample emphasizes mixeduse and compact development $(65.0 \%$ breadth, $88.5 \%$ depth). In addition, many plans require utilizing green building and green infrastructure $(60.0 \%$ breadth, $83.3 \%$ depth). Surprisingly, only $37.5 \%$ of plans paid attention to infill development and reuse of remediated brownfield sites, and only $35.0 \%$ of plans adopted growth control policies to

Table 6. Analysis plan component indicator performance.

\begin{tabular}{lcc}
\hline Indicators & Breadth (\%) & Depth (\%) \\
\hline Emissions inventory & $87.5 \%$ & $88.6 \%$ \\
Base year emission & $82.5 \%$ & $89.4 \%$ \\
Emission trends forecast & $82.5 \%$ & $87.9 \%$ \\
Vulnerability assessment & $15.0 \%$ & $83.3 \%$ \\
Cost estimates for GHG emission reduction & $65.0 \%$ & $80.8 \%$ \\
Using analysis tools & $52.5 \%$ & $85.7 \%$ \\
\hline
\end{tabular}




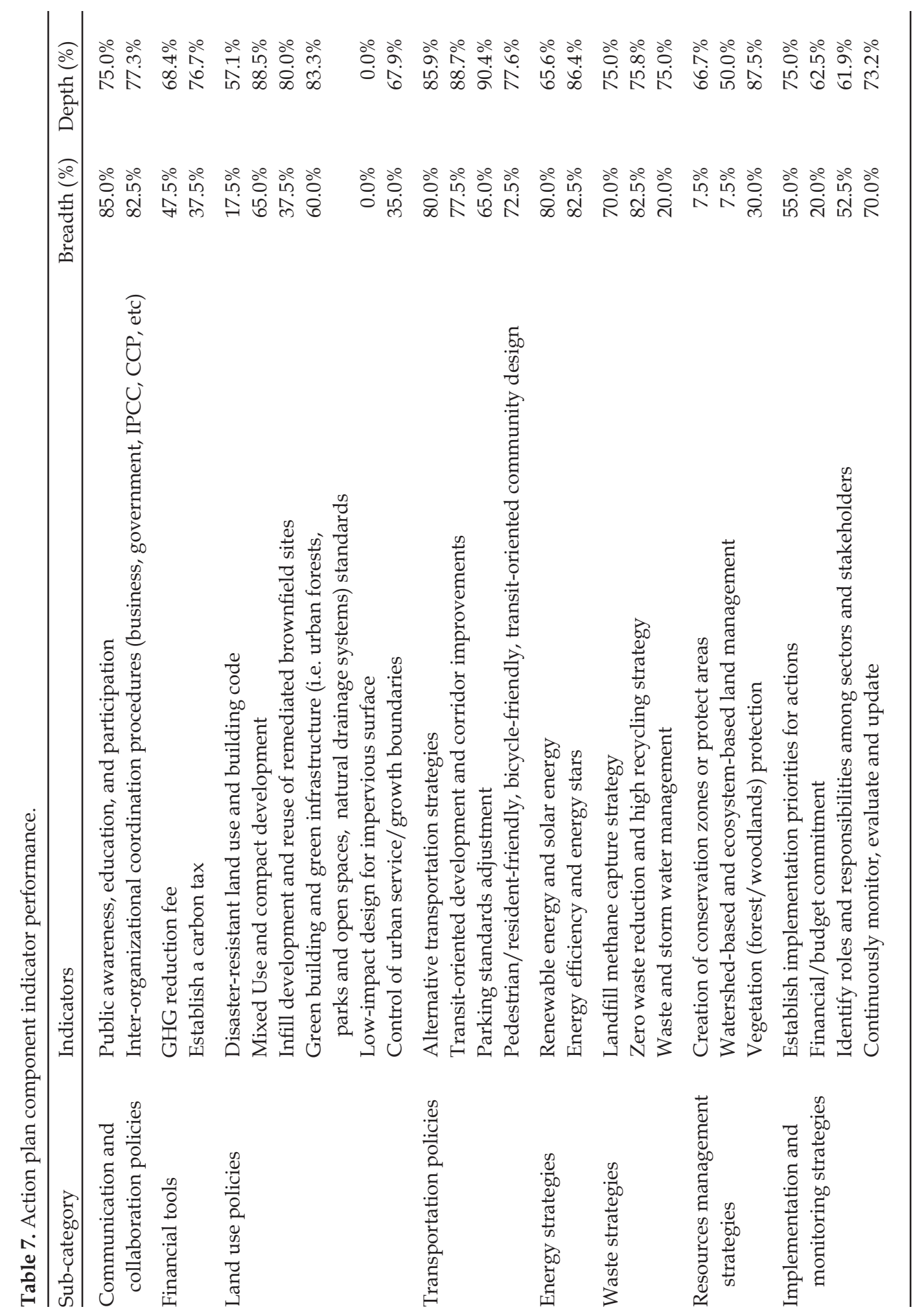


address climate change. Moreover, only 17.5\% mentioned disaster-resistant land use and building codes in their plans. Most importantly, none of the plans adopted low-impact design standards for impervious surfaces.

4.2.3.4. Transportation policies. A majority of plans emphasize using alternative transportation strategies $(80.0 \%$ breadth, $85.9 \%$ depth), and transit-oriented development and corridor improvements $(77.5 \%$ breadth, $88.7 \%$ depth). Many $(72.5 \%)$ jurisdictions also recognize pedestrian-friendly, bicycle-friendly, transit-oriented community design to reduce GHG emissions. Finally, approximately two-thirds (65\%) of the sample commit to an adjustment of existing parking standards and prices.

4.2.3.5. Energy strategies. $80.0 \%$ of plans emphasized using renewable energy (e.g. solar energy, wind energy), and $82.5 \%$ of them ask for energy efficiency and energy star polices.

4.2.3.6. Waste strategies. Many jurisdictions have adopted a landfill methane capture strategy $(70.0 \%$ breadth), and waste reduction and recycling strategy (82.5\% breadth). However, waste and storm water management received less attention in the plans.

4.2.3.7. Resources management strategies. Local climate change plans paid less attention to resource management strategies in GHG reduction and climate change mitigation. Only $7.5 \%$ of plans adopted policies to protect critical environmental areas and conservation zones. In addition, policies with watershed-based and ecosystem-based land management initiatives were rarely $(7.5 \%$ breadth, $50.0 \%$ depth) adopted in among plans in the sample.

4.2.3.8. Implementation and monitoring strategies. $70.0 \%$ of plans emphasized continuous monitoring, evaluation and updating. Slightly more than half $(55.0 \%)$ of the plans established implementation priorities for climate change actions. $52.5 \%$ of plans identify roles and responsibilities among sectors and stakeholders. However, only $20.0 \%$ make financial and budget commitment for implementation.

\subsection{Regression results for independent variables}

Multiple regression analyses are used to identify which variables among risk, stress and capacity categories significantly influence of the quality of adopted climate change action plans. Due to the small sample size, variables are analyzed by categories and then a fullyspecified model based on statistical significance of individual predictors is examined (following Brody 2003). The results in Table 8 help form a better understanding of the specific conditions that lead to strong local climate change plans.

Based on the model analyzing capacity variables, state mandates to adopt a climate change plan significantly increase plan quality at the local level $(p<0.05)$. This result coincides with previous plan quality studies demonstrating the effectiveness of state regulatory requirements on enhancing plans for local jurisdictions. The other two variables in the model, political will and community wealth, are not significant predictors of local cli- 
Table 8. Factors influencing climate change plan quality.

\begin{tabular}{|c|c|c|c|c|c|}
\hline Type of variables & Name & Coeff. & $\begin{array}{l}\text { Stand. } \\
\text { Coeff. }\end{array}$ & $t$-value & $p$-value \\
\hline Climate change capacity & $\begin{array}{l}\text { Political will } \\
\text { State mandates } \\
\text { Wealth } \\
N=40 ; \text { F-ratio }(3,36)=1.77\end{array}$ & $\begin{array}{l}1.363 \\
13.308 \\
-0.045 \\
\text { gnificance }=\end{array}$ & $\begin{array}{c}0.150 \\
0.325 \\
-0.144 \\
169 ; \mathrm{Ad}\end{array}$ & $\begin{array}{r}0.953 \\
2.065 \\
-0.923 \\
\text { ted } R^{2}=\end{array}$ & $\begin{array}{l}0.347 \\
0.046^{* *} \\
0.362 \\
0.056\end{array}$ \\
\hline Climate change risk & $\begin{array}{l}\text { Coastal distance } \\
\text { Population density } \\
\text { Hazard damages } \\
N=40 ; \text { F-ratio }(3,36)=1.66\end{array}$ & $\begin{array}{l}-0.072 \\
1.034 \mathrm{E}-05 \\
-1.712 \mathrm{E}-05 \\
\text { ignificance }\end{array}$ & $\begin{array}{c}-0.005 \\
0.007 \\
-0.350 \\
.191 ; \mathrm{Ad}\end{array}$ & $\begin{array}{r}-0.033 \\
0.043 \\
-2.161 \\
\text { ted } R^{2}=\end{array}$ & $\begin{array}{c}0.974 \\
0.966 \\
0.037^{\text {** }} \\
0.049\end{array}$ \\
\hline Climate change stress & $\begin{array}{l}\text { Energy consumption } \\
\text { Light transportation } \\
\text { Vehicular emission } \\
\text { Average commuting time } \\
N=40 ; \text { F-ratio }(5,34)=2.01\end{array}$ & $\begin{array}{l}-0.007 \\
8.120 \\
0.010 \\
-0.556 \\
\text { ignificance }\end{array}$ & $\begin{array}{r}-0.166 \\
0.147 \\
0.312 \\
-0.450 \\
.114 ; \mathrm{Ad}\end{array}$ & $\begin{array}{r}-1.050 \\
0.942 \\
1.849 \\
-2.577 \\
\text { ted } R^{2}=\end{array}$ & $\begin{array}{c}0.301 \\
0.353 \\
0.073^{*} \\
0.014^{* *} \\
0.094\end{array}$ \\
\hline Fully specified model & $\begin{array}{l}\text { State mandates } \\
\text { Vehicular emission } \\
\text { Average commuting time } \\
\text { Hazard damages } \\
N=40 ; \text { F-ratio }(4,35)=6.87 \\
\text { Significance }=0.000^{* *} \text {; Adju }\end{array}$ & $\begin{array}{l}15.291 \\
0.016 \\
-0.522 \\
-2.191 \mathrm{E}-05 \\
\mathrm{~d} R^{2}=0.376\end{array}$ & $\begin{array}{r}0.373 \\
0.482 \\
-0.423 \\
-0.447\end{array}$ & $\begin{array}{r}2.914 \\
3.294 \\
-3.024 \\
-3.373\end{array}$ & $\begin{array}{l}0.006^{* *} \\
0.002^{* *} \\
0.005^{* *} \\
0.002^{* *}\end{array}$ \\
\hline
\end{tabular}

* Significant at 0.10 level

** Significant at 0.05 level

mate change plan quality. In addition, hazard damage in the climate change risk model appears to significantly influence the quality of local climate change plans $(p<0.05)$, but in the negative direction. In contrast, several variables in the climate change stress model seem to strongly affect the quality of adopted local plans. Most prominently, increasing commuting times associated with greater amounts of $\mathrm{CO}_{2}$ emissions reduces the quality of local plans to mitigate the adverse impacts of climate change $(p<0.05)$. An increasing number of vehicles on the road is also statistically significant $(p<0.1)$ but in the positive direction.

In the fully-specified model, statistically significant variables from each preceding subregression model are analyzed. As shown in Table 8, all four independent variables are statistically significant at the 0.05 level despite the small sample size. State mandates and vehicle emissions both increase the quality of local climate change plans, while a unit increase in commuting time is associated with a decrease in the ability of local plans to address the climate change issue. In addition, a unit increase in hazard damages is associated with a decrease in the ability of local plans to address the climate change issue.

\section{Discussion and policy implications}

This study found that a majority of the 40 local jurisdictions have active awareness and adequate understanding of climate change. Jurisdictions have higher awareness because 
they are at the forefront of climate change action planning. The most persuasive explanation for this result is that the local jurisdictions represented in the study are pioneers in the US to take serious actions to address climate change at the local level. Although 157 jurisdictions have joined the $\mathrm{CCP}$ and 850 mayors have signed the climate change agreement, these 40 jurisdictions are the first actors to adopt concrete local climate change action plans. Therefore, it is not surprising for these 40 jurisdictions with local climate change action plans to have clear awareness and high motivation to take actions in mitigating climate change. Of course, it is also important to further increase decision makers' awareness of future impacts on climate change and help them understand how preparedness for climate change can be integrated into daily decision making (Rayner and Malone 1997, Bulkeley 2000). Adequate understanding of potential adverse impacts can encourage local jurisdictions to commit themselves to climate change mitigation. Local jurisdictions can also increase public awareness to encourage developers and individuals to adopt climate-friendly and environmentally efficient practices. The channels of awareness include: (1) hands-on training; (2) user manuals; (3) workshops; (4) school education; (5) web-based information; (6) dedicated list-serves, etc. All of these approaches help build up stronger political commitment to deal with climate change.

While the evaluated plans generally made detailed emissions inventory and trends, few linked emission data geographically. Localizing global climate change is the first step in getting jurisdictions to develop action policies to mitigate climate change and control their GHG emissions. Although much large-scale information on climate change has been widely disseminated, local jurisdictions should link this information with local policies. In many instances, local jurisdictions may feel that climate change is a global issue and this creates an inability or reluctance to integrate global scientific input into local action plans. Thus, it is necessary to provide professional training to enhance institutional capacity to stay abreast of the trends in relevant climate change information. Since most current climate change studies are conducted at regional, national or global levels, it is a constant challenge for local jurisdictions to integrate the information at the local level.

The findings of this study have identified only moderate analysis capabilities in existing local climate change action plans. Some jurisdictions were not using all of the planning tools available. Local planners must analyze the impacts of climate change by reviewing major emission sources in their planning area and linking these results with local planning policies. Local climate change action plans should also better identify critical thresholds in climate-sensitive sectors and analyze the socio-economically and racially differentiated vulnerabilities from climate change. In addition, local plans should identify constraints and stressors in climatic, economic, technological, institutional, social, legal and ecological fields. These analysis capabilities can be improved through building a long-term database with local climate and hydrology records. A climate sensitivity analysis should also examine current plans and ordinances to ensure climate change mitigation and adaptation is taking place.

One of the major findings of this study is that current local climate change action plans focus predominantly on the built environment (e.g. energy, transportation, wastes and buildings) and pay little attention to the natural environment. In addition, although these plans made appropriate policies in communication and coordination, relatively few strategies were employed for implementation. Local jurisdictions need more innovative policies, tools and strategies to respond to climate change (e.g. carbon tax, carbon fees). Local jurisdictions have considerable authority for land development, waste man- 
agement, transportation planning, and can play more critical roles in climate change mitigation (Collier and Lofstedt 1997, Rayner and Malone 1997, Agyeman et al. 1998, DeAngelo and Harvey 1998, Kates and Torrie 1998, Kates et al. 1998, Bulkeley 2000, Betsill 2001). Although the strategies for climate change mitigation and adaptation have increasingly gained attention in research and policy communities, the results indicate that local jurisdiction discourse remains limited with regard to the many critical strategies for mitigation and adaptation. Local jurisdictions should expand their policies, tools and strategies for climate change. The previous research suggests the need to design policy instruments for real world conditions rather than trying to make the existing world conform to a particular policy (Rayner and Malone 1997). Studies have highlighted that some traditional planning policies (e.g. vehicle emission reduction) have been well adopted in current plans for climate change; however, new policies, tools, and strategies (e.g. carbon trade policy, tax abatement) were not well considered in local climate change action plans. This suggests local jurisdictions should adopt more incentives, such as regional initiatives, and natural resource management initiatives (Mayors' Climate Protection Center, 2007), to mitigate and adapt to climate change. Finally, the results also indicate that local jurisdictions tend to pay more attention to reducing climate change impacts (e.g. transportation policies, energy strategies) rather than preparing for the consequences (resources management strategies, disaster-resistant land use and building codes).

The explanatory results identified several contextual factors influencing local climate change action plan quality. By far, the most significant predictor contributing to higher quality plans is the presence of state mandates. As shown in previous studies on plan quality focusing on different topics such as natural hazards (Berke et al. 1996, Brody et al., 2003, Burby 2005), top-down directives at the state level exerts pressure on localities to enact strong measures to address the climate change problem. In fact, the presence of a mandate increases the plan quality score by nearly 14.5 points. It is suspected that state mandates are so critical in this context because local jurisdictions may not yet feel climate change mitigation is their responsibility. As mentioned above, this issue is often considered a national or regional problem outside the domain for local communities. Mandates thus provide the essential motivation for localities to adopt strong climate change plans while the issue is still relatively novel in the local governmental consciousness.

The study also found that the transportation-related issues, such as vehicular emission and average commuting time, can significantly contribute to local climate change plan quality. Specifically, more vehicles on the road generating higher amounts of GHG emissions appear to motivate local decision makers to adopt higher quality plans. Over-reliance on automobiles is an issue well suited to local planning initiatives. Jurisdictions can respond to traffic congestion by using local planning powers to offer alternative modes of transportation such as bus and train. Indeed, the results show that $80 \%$ of the plans in the sample included alternative transportation strategies and over $77 \%$ included transit oriented developments. In contrast, longer commuting times that are indicative of a sprawling pattern of regional development significantly lowers the climate change plan quality measure. This result is expected because localities with a poor history of planning may find it politically difficult to abruptly enact strong development controls or may be less interested in adopting plans that genuinely address the potential adverse impacts of climate change. 
Finally, it was found that the direction of hazard damage variable runs counter to previous studies in which hazards are positive motivators for climate change initiatives. The past studies show that frequent experience with hazards will more probably lead to participation in climate programs (Brody et al. 2008b, Zahran et al. 2008b). However, participation in a program does not necessarily mean the adopted plan will be stronger. The logic behind such a disconnect between hazard experience and climate change plan quality could be: (1) localities may be preoccupied with the immediate, short-term concern of reducing hazard damage than longer, more abstract issues like climate change. Directing energy and resources to addressing immediate concerns could result in a weaker climate change plan if the two issues are not considered integrally linked; (2) communities with large amounts of hazard damage tend to have a poor record for planning, development management and concern for environmental impacts. These communities have less of a desire to adopt a high quality plan and could be involved in the program only to satisfy a state mandate or for publicity reasons. From a planning perspective, local jurisdictions should be looking both at ways to reducing community's footprint and/or addressing community impacts of climate change. They are all important approaches to achieve local sustainable development goals. The results have found that the lack of emphasis on land use and resource management strategies in those climate change action plans. This result helps to explain the direction of the hazard damage risk factor. If climate change action plans do not address risk reduction, then they may be less relevant to high-risk jurisdictions.

\section{Conclusion}

This study found significant variation in the quality of adopted local climate change plans across the US and specific factors that contribute to their relative strengths and weaknesses. While this analysis is the first to examine climate change plans using plan evaluation techniques, it should be considered only an initial step in exploring the topic. First, the sample was limited to only 40 plans. Future research should examine larger samples providing greater power to make statistical conclusions and permitting the inclusion of more independent variables in the same model. Given the surge in interest from localities to address the impacts of climate change, it is expected that more jurisdictions will adopt plans in the future. Second, the analysis was limited to plans focusing exclusively on climate change. Other types of regulatory documents, such as comprehensive, transportation or natural hazards plans also tend to include specific provisions that mitigate the negative effects of climate change. These plans, which traditionally have the greatest influence on the way local communities develop, should also be the focus for future inquiry. Third, the study is limited to evaluating the quality of existing local climate change plans. Perhaps a more pertinent research question is whether these plans make a difference in reducing stressors on the climate change problem and risk to vulnerable population. Additional research needs to be conducted on the degree to which plans are reducing GHG emissions and fostering resilient and sustainable communities. Fourth, local climate change action planning is a dynamic and long-term process. The research was limited to a single period (i.e. the year 2008), which may not clearly reflect the progress of local climate change action planning. It is recognized that many jurisdictions involved in this study are still improving their initial local climate change plans. As plans and policies have more time to develop, longitudinal analysis will better pinpoint the factors con- 
tributing to policy learning in response to the growing problem of climate change. Fifth, the scope of this paper only focuses on evaluating plan quality for the jurisdictions that have initiated local climate change action plans. The study did not compare differences between jurisdictions with climate plans and others without them, and it is recognized that some explanatory variables (e.g. climate risk) may be more likely to drive the decision to plan than plan quality itself. In future studies, the authors will compare the climate change action capacities of the two types of jurisdictions. Finally, a higher plan quality may not automatically mean good action in practice. Future studies should address the implementation effectiveness of local climate change planning. Moreover, the future study will use the subset of climate policies (e.g. land use, resource management, transportation, etc.) as a new dependent variable to further identify the relationship between risk and the types of climate actions used in local jurisdictions.

\section{Acknowledgments}

The authors really appreciate three anonymous reviewers for their valuable comments and help in improving an earlier version of this article. This research is supported by Hyde Professorship Fund and Layman Award from University of Nebraska-Lincoln, but the findings and opinions reported in this paper are not necessarily endorsed by the funding organization.

\section{Notes}

1. Total and component quality is calculated by the following equations:

and

$$
P C_{j}=\frac{10}{2 m_{j}} \sum_{i=1}^{m_{j}} I_{i}
$$

$$
T P Q=\sum_{j=1}^{3} P C_{j}
$$

where $P C_{j}$ represents the quality of the $j$ th plan component (ranging $0-10$ ); $m_{j}$ represents the number of indicators within the $j$ th plan component; $I_{i}$ represents the $i$ th indicator's score (ranging 0-2); and TPQ is the total score of a whole plan (ranging 0-30).

2. Indicator breadth is calculated as the equation: $I B S_{j}=P_{j} / N \times 100$

Indicator depth is calculated as the equation:

$$
I D S_{j}=\frac{\sum_{j=1}^{P_{j}} I_{j}}{2 P_{j}} \times 100
$$

$I B S_{j}$ is the $j$ th indicator breadth score (scale $0-100 \%$ ); $P_{j}$ is number of plans that address the $j$ th indicator; $N$ is total number of plans in the study; $I D S_{j}$ is the $j$ th indicator depth score (scale 50 $100 \%$ if at least one plan addresses this indicator; if none of the plans address this indicator, the score is 0 ); $I_{j}$ is the $j$ th indicator received scores (scale $0-2$ ).

\section{References}

Agyeman, J., Evans, B., and Kates, R. W., 1998. Greenhouse gases special: Thinking locally in science, practice and policy. Local Environment, 3 (3), 382-383.

APA (American Planning Association), 2008. Policy Guide on Planning \& Climate Change: http:// www.planning.org/policyguides/pdf/draftclimatechange.pdf (accessed July 3, 2008).

Andrews, C. J., 2008. Energy conversion goes local: Implications for planners. Journal of the American Planning Association, 74 (2), 231-254.

Angel, D. P., et al., 1998. The drivers of Greenhouse Gas emissions: What do we learn from local case studies? Local Environment, 3 (3), 263-277. 
Berke, P. R., 2002. Does sustainable development offer a new direction for planning? Challenges for the twenty-first century. Journal of Planning Literature, 17, 21-36.

Berke, P. R. and Conroy, M. M., 2000. Are we planning for sustainable development? An evaluation of 30 comprehensive plans. Journal of the American Planning Association, 66, 21-33.

Berke, P. R., Dixon, J., and Ericksen, N., 1997. Coercive and cooperative intergovernmental mandates: A comparative analysis of Florida and New Zealand environmental plans. Environment and Planning B: Planning \& Design, 24, 451-468.

Berke, P. R. and French, S. P., 1994. The influence of state planning mandates on local-plan quality. Journal of Planning Education and Research, 13, 237-250.

Berke, P. R., et al., 1996. Enhancing plan quality: Evaluating the role of state planning mandates for natural hazard mitigation. Journal of Environmental Planning and Management, 39, 79-96.

Betsill, M. M., 2001. Mitigating climate change in US cities: Opportunities and obstacles. Local Environment, 6 (4), 393-406.

Bizikova, L., Robinson, J., and Cohen, S., 2007. Linking climate change and sustainable development at the local level. Climate Policy, 7 (4), 271-277.

Brody, S. D., 2003. Measuring the effects of stakeholder participation on the quality of local plans based on the principles of collaborative ecosystem management. Journal of Planning Education and Research, 22, 407-419.

Brody, S. D., Godschalk, D. R., and Burby, R. J., 2003. Mandating citizen participation in plan making-Six strategic planning choices. Journal of the American Planning Association, 69, 245-264.

Brody, S. D., Highfield, W., and Carrasco, V., 2004. Measuring the collaborative planning capabilities of local jurisdictions to manage ecological systems in southern Florida. Landscape and Urban Planning, 69, 33-50.

Brody, S. D., et al., 2008a. A spatial analysis of local climate change policy in the U. S. : Risk, stress, and opportunity. Landscape and Urban Planning, 87 (1), 33-41.

Brody, S. D., et al., 2008b. Examining the relationship between physical vulnerability and perceptions of global climate change in the U. S. Environment and Behavior, 40 (1), 72-95.

Bulkeley, H., 2000. Down to earth: Local government and greenhouse policy in Australia. Australian Geographer, 31 (3), 289-308.

Burby, R. J., 2005. Have state comprehensive planning mandates reduced insured losses from natural disasters? Natural Hazards Review, 6 (2), 67-81.

Burby, R. J. and Dalton, L. C., 1994. Plans can matter-The role of land-use plans and state planning mandates in limiting the development of hazardous areas. Public Administration Review, 54, 229-238.

Burby, R. J., et al., 2000. Creating hazard resilient communities through land-use planning. Natural Hazards Review, 1 (2), 99-106.

Burton, I., et al., 2007. Integrating adaptation into policy: Upscaling evidence from local to global. Climate policy, 7 (4), 371-376.

California Air Resources Board, California Climate Action Registry, ICLEI-Local Governments for Sustainability The Climate Registry, 2008. Draft local government operations protocol : http://counties.org/images/users/1/Climate\%20Change\%20-\%20Draft_lgo_protocol_2008-0619\%20(2).pdf (accessed November 10, 2008).

California Climate Change Center, 2006. Preparing for the impacts of climate change in California: opportunities and constraints for adaptation: http://www.energy.ca.gov/2005publications/ CEC-500-2005-198/CEC-500-2005-198-SF.PDF (accessed July 3, 2008).

Center for Science in the Earth System, University of Washington; King County, Washington. ICLEI-Local Governments for Sustainability 2007. Preparing for climate change. A guidebook for local, regional, and state governments: http://www.cses.washington.edu/db/pdf/snoveretalgb574.pdf (accessed November 10, 2008). 
Collier, U. and Lofstedt, R., 1997. Think globally, act locally? Local climate change and energy policies in Sweden and the UK. Global Environmental Change, 7 (1), 25-40.

Conroy, M. M. and Berke, P. R., 2004. What makes a good sustainable development plan? An analysis of factors that influence principles of sustainable development. Environment and Planning A, 36, 1381-1396.

Dalton, L. C. and Burby, R. J., 1994. Mandates, plans, and planners - Building local commitment to development management. Journal of the American Planning Association, 60 (4), 444-461.

DeAngelo, B. and Harvey, L. D., 1998. The jurisdictional framework for municipal action to reduce greenhouse gas emissions: Case studies from Canada, USA and Germany. Local Environment, 3 (2), 111-136.

Edwards, M. M. and Haines, A., 2007. Evaluating smart growth implications for small communities. Journal of Planning Education E Research, 27, 49-64.

Forester, J., 1984. Bounded rationality and the politics of muddling through. Public Administration Review, 44, 23-31.

IPCC (Intergovernmental Panel on Climate Change), 2007. An Assessment of the Intergovernmental Panel on Climate Change - Climate Change 2007: Synthesis Report (Fourth Assessment Report): http:// www.ipcc.ch/pdf/assessment-report/ar4/syr/ar4_syr.pdf (accessed May 26, 2008).

ICLEI (International Council for Local Environmental Initiatives), 2008. International local government Greenhouse Gas (GHG) protocol : http:// www.iclei.org/ (accessed October 26, 2008).

Kates, R. W. and Torrie, R. D., 1998. Global change in local places. Environment, 40 (2), 39-41.

Kates, R. W., et al., 1998. Methods for estimating greenhouse gases from local places. Local Environment, 3 (3), 279-297.

Lindley, S. J., et al., 2006. Adaptation strategies for climate change in the urban environment: assessing climate change related risk in UK urban areas. Journal of Risk Research, 9 (5), 543-568.

Lindseth, G., 2004. The cities for Climate Protection Campaign (CCPC) and the framing of local climate policy. Local Environment, 9 (4), 325-336.

Mayors Climate Protection Center, 2007. Climate Protection Strategies and Best Practices Guide. 2007 Mayors Climate Protection Summit Edition. Seattle, WA: Mayors Climate Protection Center: http://USmayors.org/climateprotection/documents/2007bestpractices-mcps.pdf $\quad$ (accessed January 4, 2009).

Moser, S. C. and Luers, A. L., 2008. Managing climate risks in California: The need to engage resource managers for successful adaptation to change. Climate Change, 87 (1), 309-322.

Moser, S. C. and Tribbia, J., 2006. Vulnerability to inundation and climate change impacts in California: Coastal managers' attitudes and perceptions. Marine Technology Society Journal, 40 (3), 4-13.

Nelson, H. T., 2008. Planning implications from the interactions between renewable energy programs and carbon regulation. Journal of Environmental Planning and Management, 51 (4), 581-596.

Nelson, A. C. and French, S. P., 2002. Plan quality and mitigating damage from natural disastersA case study of the Northridge Earthquake with planning policy considerations. Journal of the American Planning Association, 68, 194-207.

Norton, R. K., 2005. Local commitment to state-mandated planning in coastal North Carolina. Journal of Planning Education Research, 25, 149-171.

Nunnally, J. C., 1978. Psychometric Theory. 2nd ed. New York: McGraw-Hill.

Olshansky, R. B., 2001. Comprehensive land use planning for seismic safety: The Los Angeles county experience, 1971-1994. Journal of the American Planning Association, 67 (2), 173-185.

Rayner, S. and Malone, E. L., 1997. Zen and the art of climate maintenance. Nature, 390, 332- 334.

Scott, D. and Willits, F. K., 1994. Environmental attitudes and behavior. Environment and Behavior, 26 (2), 239-261.

Stern, N., 2007. The Economics of Climate Change. Cambridge: Cambridge University Press. 
Swart, R. and Raes, F., 2007. Making integration of adaptation and mitigation work: Mainstreaming into sustainable development policies? Climate Policy, 7 (4), 288-303.

Tang, Z., 2008. Evaluating the capacities of local jurisdictions' coastal zone land use planning in California. Ocean and Coastal Management, 51 (7), 544-555.

Tang, Z., et al., 2008. Measuring tsunami hazard planning capacity on the U. S. Pacific Coast. Natural Hazards Review, 9 (2), 91-100.

Tang, Z. and Brody, S. D., 2009. Link planning theories with factors influencing local environmental plan quality. Environmental and Planning B: Planning and Design, 36, 522-537.

Tang, Z., Bright, E., and Brody, S. D., 2009. Evaluating California local land use plans' environmental impact reports. Environmental Impact Assessment Review, 29, 96-106.

Travis, W. R., 2008. Global warming and land use. Draft for presentation at the Rocky Mountain Land Use Institute University of Denver, March: http://www.agci.org/index.html (accessed July 3, 2008).

UKCIP (United Kingdom Climate Impacts Group), 2003. Climate change and Local Communities. How Prepared Are You? Oxford: UKCIP: http://www.idea.gov.uk/idk/aio/396539 (accessed August $8,2008)$.

Van Liere, K. D. and Dunlap, R. E., 1981. Environmental concern-Does it make a difference how it's measured? Environmental Behavior, 13, 651-676.

Yarnal, B., O'Connor, R. E., and Shudak, R., 2003. The impact of local versus national framing on willingness to reduce Greenhouse Gas Emissions: A case study from central Pennsylvania. Local Environment, 8 (4), 457-469.

Wheeler, S. M., 2008. State and municipal climate change plans: The first generation. Journal of the American Planning Association, 74 (4), 481-496.

Zahran, S., et al., 2008a. Explaining local commitment to climate change policy in the United States. Environment and Planning C, 26 (3), 544-562.

Zahran, S., et al., 2008b. Risk, stress, and capacity: Explaining metropolitan commitment to climate protection. Urban Affairs Review, 43, 475-496. 
Appendix 1. Local climate change plan quality across jurisdictions.

\begin{tabular}{|c|c|c|c|c|c|}
\hline Jurisdictions & State & Total quality & Awareness & Analysis & Actions \\
\hline Austin & $\mathrm{TX}$ & 5.35 & 3.75 & 0.83 & 0.77 \\
\hline Santa Cruz & CA & 6.54 & 2.50 & 2.50 & 1.54 \\
\hline Evanston & IL & 6.83 & 3.75 & 0.00 & 3.08 \\
\hline Maplewood & NJ & 7.21 & 6.25 & 0.00 & 0.96 \\
\hline Fort Collins & $\mathrm{CO}$ & 7.82 & 5.00 & 1.67 & 1.15 \\
\hline Portland & ME & 8.56 & 3.75 & 2.50 & 2.31 \\
\hline Chapel Hill & $\mathrm{NC}$ & 8.75 & 6.25 & 2.50 & 0.00 \\
\hline Miami-Dade County & FL & 9.13 & 8.75 & 0.00 & 0.38 \\
\hline Montgomery County & MD & 10.58 & 5.00 & 2.50 & 3.08 \\
\hline Salt Lake City & UT & 11.83 & 8.75 & 0.00 & 3.08 \\
\hline Jefferson County & WA & 12.08 & 3.75 & 8.33 & 0.00 \\
\hline Davis & CA & 12.24 & 5.00 & 6.67 & 0.58 \\
\hline Benicia & CA & 13.30 & 6.25 & 6.67 & 0.38 \\
\hline Boston & MA & 15.06 & 7.50 & 3.33 & 4.23 \\
\hline Menlo Park & CA & 15.83 & 7.50 & 8.33 & 0.00 \\
\hline Somerville & MA & 16.51 & 8.75 & 3.33 & 4.42 \\
\hline Seattle & WA & 16.70 & 8.75 & 3.33 & 4.62 \\
\hline Charleston & SC & 17.47 & 8.75 & 5.83 & 2.88 \\
\hline Homer & $\mathrm{AK}$ & 17.60 & 8.75 & 2.50 & 6.35 \\
\hline Marin County & CA & 18.43 & 8.75 & 5.83 & 3.85 \\
\hline Aspen & $\mathrm{CO}$ & 19.01 & 8.75 & 5.83 & 4.42 \\
\hline Anacortes & WA & 19.29 & 7.50 & 8.33 & 3.46 \\
\hline Duluth & $\mathrm{MN}$ & 19.87 & 7.50 & 8.33 & 4.04 \\
\hline Brattleboro & VT & 20.16 & 8.75 & 5.83 & 5.58 \\
\hline Pittsburgh & PA & 20.16 & 8.75 & 5.83 & 5.58 \\
\hline Durham & $\mathrm{NC}$ & 20.38 & 7.50 & 7.50 & 5.38 \\
\hline Sonoma County & CA & 20.61 & 8.75 & 6.67 & 5.19 \\
\hline Worcester & MA & 20.74 & 8.75 & 5.83 & 6.15 \\
\hline San Diego & CA & 21.25 & 8.75 & 7.50 & 5.00 \\
\hline Philadelphia & PA & 22.08 & 8.75 & 8.33 & 5.00 \\
\hline Denver & $\mathrm{CO}$ & 22.28 & 8.75 & 8.33 & 5.19 \\
\hline San Francisco & CA & 23.24 & 8.75 & 8.33 & 6.15 \\
\hline Boulder & $\mathrm{CO}$ & 23.59 & 10.00 & 6.67 & 6.92 \\
\hline Portland & OR & 23.62 & 8.75 & 8.33 & 6.54 \\
\hline Alameda & CA & 24.29 & 10.00 & 8.33 & 5.96 \\
\hline Keene & $\mathrm{NH}$ & 25.26 & 10.00 & 8.33 & 6.92 \\
\hline Madison & WI & 25.64 & 10.00 & 8.33 & 7.31 \\
\hline Berkeley & CA & 25.90 & 10.00 & 9.17 & 6.73 \\
\hline Bellingham & WA & 26.54 & 10.00 & 10.00 & 6.54 \\
\hline King County & WA & 28.65 & 10.00 & 10.00 & 8.65 \\
\hline
\end{tabular}

The maximum score for total plan quality is 30.00 . The maximum score for each plan component of awareness, analysis and action is 10.00 . 